\title{
Profit Sharing Using a Dynamic Reinforcement Function Considering Expectation Value of Reinforcement
}

\author{
Daisuke Tamashima Member (Chiba University) \\ Seiichi Koakutsu Senior Member (Chiba University) \\ Takashi Okamoto Member (Chiba University) \\ Hironori Hirata Senior Member (Chiba University)
}

Keywords: reinforcement learning, profit sharing, reinforcement function, ineffective rule suppression theorem

Profit Sharing is one of exploitation oriented reinforcement learning and aims to adapt a system to a given environment. In Profit Sharing, an agent learns a policy based on the reward that is received from the environment when it reaches a goal state. It is important to design a reinforcement function that distributes the received reward to each action rule in the policy. If the reinforcement function satisfies the ineffective rule suppression theorem, the reinforcement function is able to distribute more reward to effective rules than ineffective rules, even in the worst case where an ineffective rule is infinitely selected. The value of the reinforcement function, however, decreases exponentially with distance from the goal state. As a result, the agent fails to learn an appropriate policy when the episode length from an initial state to the goal state is relatively long. In order to solve this problem, Simplified Dynamic Profit Sharing (SDPS) has been proposed. SDPS uses a dynamic reinforcement function that dynamically changes the decrease ratio of reinforcement so as to suppress a decrease in the value of the reinforcement function.

In this paper, we propose a new modified Profit Sharing which uses a new dynamic reinforcement function, considering the expected value of reward which is di stributed to each rule. Using the proposed reinforcement function, the expected value of reward distributed to the effective rules becomes larger than that to the ineffective rules. Even when the episode length becomes long, a decrease in the value of the reinforcement function is able to be suppressed, and thus the agent is able to learn an appropriate policy. Moreover, the proposed reinforcement function has three additional benefits. First, the proposed reinforcement function is derived from the same elicitation process of the ineffective rule suppression theorem, so the relation of the proposed reinforcement function to the ineffective rule suppression theorem is clear. Second, in the elicitation process of the proposed reinforcement function, no additional parameter such as the threshold value of SDPS is necessary. Lastly, in the pro-

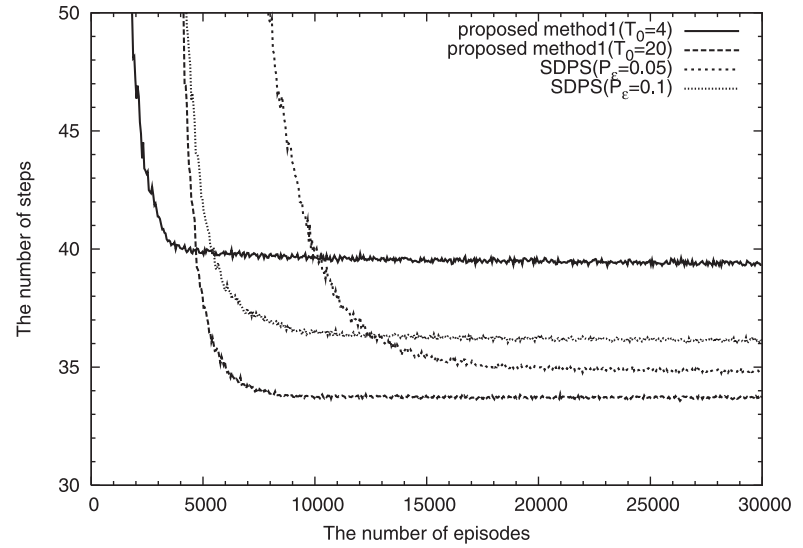

Fig. 1. Experimental results of extended Sutton's maze problem

posed reinforcement function, there exists a parameter $T_{0}$ which adjusts a trial and error process span, and thus we can balance the learning speed with the quality of learning results adjusting $T_{0}$.

To evaluate the proposed method, we apply it to an extended Sutton's maze problem, and compare the proposed method with SDPS. The extended Sutton's maze is a maze in which each mass of Sutton's maze is divided into $2 \times 2$ masses, and thus the episode of the extended maze is twice the length of that of Sutton's maze. Fig.1 shows the experimental results of the extended Sutton's maze problem. We can see that the learning curve of the proposed method becomes steeper than that of SDPS. On the other hand, SDPS $\left(P_{\epsilon}=0.05\right)$ obtains better learning results than the proposed method in the end. The proposed method, however, is also able to obtain the same learning results as SDPS at the expense of the learning speed, when we adjust the parameter $T_{0}$ upward. As stated above, results of computational experiments indicate the validity of the proposed method. 


\title{
期待強化值を考慮した動的強化関数を用いる Profit Sharing
}

\author{
正員 玉嶋 大輔* 上級会員 小圷 成一* \\ 正 員 岡本 卓* 上級会員 平田 廣則*
}

\author{
Profit Sharing Using a Dynamic Reinforcement Function \\ Considering Expectation Value of Reinforcement
}

\author{
Daisuke Tamashima*, Member, Seiichi Koakutsu*, Senior Member, Takashi Okamoto*, Member, \\ Hironori Hirata*, Senior Member
}

\begin{abstract}
Profit Sharing is one of exploitation oriented reinforcement learning methods and aims to adapt a system to a given environment. In Profit Sharing, an agent learns a policy based on the reward that is received from the environment when it reaches a goal state. It is important to design a reinforcement function that distributes the received reward to each action rule in the policy. If the reinforcement function satisfies the ineffective rule suppression theorem, the reinforcement function is able to distribute more reward to effective rules than ineffective ones, even in the worst case where an ineffective rule is infinitely selected. The value of the reinforcement function, however, decreases exponentially with distance from the goal state. As a result, the agent fails to learn an appropriate policy when the episode length from an initial state to the goal state is relatively long. In this paper, we report a new dynamic reinforcement function considering the expected value of reward which is distributed to each rule. Using our reinforcement function, the expected value of reward distributed to the effective rules becomes larger than that to the ineffective ones. Even when the episode length becomes long, a decrease in the value of the reinforcement function is able to be suppressed, and thus the agent is able to learn an appropriate policy. We apply our reinforcement function to Sutton's maze problem, and show its effectiveness.
\end{abstract}

キーワード : 強化学習, Profit Sharing, 強化関数, 合理性定理

Keywords: reinforcement learning, profit sharing, reinforcement function, ineffective rule suppression theorem

\section{1. まえがき}

強化学習とは，報酬という特別な入力を手掛かりとして， 試行錯誤を通じて環境に適応する機械学習の一種である。 強化学習はその強化方法によって, 最終的により多くの報 酬を得るために最適性を重視した接近である環境同定型と， 学習途中でも報酬を得る効率性を重視した接近である経験 強化型に大別できる(1)。

環境同定型の代表的手法として，Q-Learning がある。 Q-Learning では, 行動価值関数と呼ばれる関数をもとに 行動選択および行動学習を行う。環境がマルコフ決定過程 (Markov Decision Processes: MDPs) のとき，学習パラ メータを適切に調整すれば, Q-Learning は最適政策に収

\footnotetext{
* 千葉大学

干 263-8522 千葉市稲毛区弥生町 1-33

Chiba University

1-33, Yayoi-cho, Inage-ku, Chiba 263-8522
}

束することが証明されている(2)。しかし，環境同定のため に多くの試行を要するため, 特に環境が複雑になると, 必 要な試行の数が著しく増大する。一方, 経験強化型の代表 的手法として, Profit Sharing がある。Profit Sharingは 最適性よりも学習過程の効率性を重視しているため, 学習 の立ち上がりが早く, Q-Learning などに比べて学習に要す る試行の回数は一般的に少ない。また, MDPs が厳密には 成立しない不完全知覚環境の学習に強く, マルチエージェ ントシステムの代表的なベンチマーク問題である追跡問題 において, Q-Learning と Profit Sharing を応用した結果, マルチエージェント強化学習として Profit Sharing が優位 であることが実験的に示されている ${ }^{(3)}$ 。

本論文では, Proit Sharingに着目する。Profit Sharing は合理性定理 ${ }^{(4)}$ によって, 報酬を分配する強化関数の合理 性が保証されている。しかし，ルーレット選択などの行動選 択手法を用いて学習を進める場合, 強化関数值が報酬獲得 までの行動系列の長さに対して指数関数的に減少し, ルー 
ルの重みの初期值に比べて強化值が極めて小さくなるため, 目標状態までに多くの状態遷移を必要とする大規模な環境 では学習が困難になる ${ }^{(5)}$ 。そこで，行動選択手法にルーレッ 卜選択を用いる場合に特化させて，学習中にルールの重み の初期值を変更することで問題の解決をはかる手法 ${ }^{(6)}$ が提 案されている。この手法では，強化值に応じてルールの重み の初期值を逐次決定し直すことで，学習を可能にしている。 一方，強化関数を動的に決定することで，高い合理性を保 証しながら高速に学習を行う手法として, Dynamic Profit Sharing (DPS) ${ }^{(7)}$, Simplified Dynamic Profit Sharing (SDPS) (8) が提案されている。DPS は，すべての有効ルー ルの行動選択確率と一つの有効ルールの行動選択確率との 比によって有効ルールが報酬を獲得する確率を決定し，さら に，無効ルールが連続して選択される回数の上限をしきい 值パラメータによって決定する。そして, 確率的に無効ルー ルを抑制できる範囲の強化減少比を動的に求めて，ルール の重みを強化する。DPS はしきい值パラメータを適切に設 定することにより，高い合理性を維持しつつ強化減少比を 小さく抑え，大きな報酬を分配することができる。しかし， DPS は強化減少比を解析的に求めることができないため, 計算量が大きくなる問題点がある。SDPS は, DPS と比べ てより合理性の高い手法であり，解析的に強化減少比を決 定できるため，計算量を軽減できる。また，合理性に関す る検討として，ルールの期待強化值を考慮することで，強 化減少比の条件を緩和する統計的合理性定理 ${ }^{(9)}$ が提案され ている。統計的合理性定理では，行動選択手法にルーレッ 卜選択を仮定することで，任意の状態におけるすべての無 効ルールの選択確率が統計的に減少するための, 強化減少 比の条件が示されている。さらに, 有効ルールと無効ルー ルの両方の期待強化值に焦点を当てた合理性に関する理論 的考察として，期待合理性定理 ${ }^{(10)}$ が知られている。

本論文では，動的強化関数を設計する新しい手法を提案 する。DPS や SDPS では，有効ルールが報酬を獲得する 確率と無効ルールが連続して選択される回数に対して，合 理性定理を満足するための条件を緩和している。一方，提 案手法では, 無効ルールの選択確率を仮定し, 合理性定理 における無効ルールの最大強化值の代わりに，期待強化值 に対して抑制条件を設定することにより，合理性定理の条 件を直接的に緩和する。合理性定理に基づく等比減少関数 は，提案手法で導出する強化関数の特別な場合に相当する。 提案手法は DPS や SDPS と異なり, 強化関数の条件の導 出にパラメータを用いないため, より一般的に一定の合理 性を保証することができる。また，DPS，SDPS では検討 されていない大局的な合理性 ${ }^{(4)}$ についても考察を行う。提 案手法では，ある有効ルールの最小強化值と, 無効ルール の期待強化值の大小関係から, 無効ルールの期待強化值抑 制条件を導出する。よって，ルーレット選択に基づく無効 ルールの行動選択確率が，統計的に減少することを目的と する統計的合理性定理の抑制条件とは意味が異なり，提案 手法では特定の行動選択手法を仮定する必要はない。また，
本論文で提案する手法は期待合理性定理とは異なり，期待 強化值を考えるのは無効ルールのみであり, 有効ルールに 与えられる強化值は最小值を仮定する。よって, 最も無効 ルールが強化されやすい状態遷移の構造において，その無 効ルールの期待強化值抑制条件を求めれば，任意の無効ルー ルの期待強化值を抑制できる。さらに，提案手法では，導 出された無効ルールの期待強化值抑制条件を動的強化関数 の実装に応用する。提案手法の利点は, 合理性定理に基づ く等比減少関数との対比が明確であり, さらに, 合理性定 理における強化減少比の定数を大きく設定できることであ る。なぜなら，十分条件以上に強化減少比の定数を大きく しても, 強化減少比が小さく抑えられれば報酬を分配でき るからである。この強化減少比の定数を大きく設定すると, 試行錯誤の期間を長くとることができるため，より良い解 を得ることが期待できる。

以降，2. では記号の準備について述べ，3. では従来の Profit Sharing，および提案手法について述べる。そして， 4. で計算機実験と，実験結果に対する考察を行い，最後に 5. で本論文を総括し，今後の課題を述べる。

\section{2. 準 備}

はじめに，本論文で用いる記号を準備する。以降，学習 主体をエージェントと呼ぶ。エージェントが観測する状態 集合を $\mathcal{S}:=\left\{s_{1}, s_{2}, \cdots, s_{I}\right\}$, エージェントの行動集合を $\mathcal{A}:=\left\{a_{1}, a_{2}, \cdots, a_{J}\right\}$ とする。各集合の大きさは $|\mathcal{S}|=I$, $|\mathcal{A}|=J$ である。報酬は $r$ で表す。本論文では, 副報酬は 考えない。また, $t(t=1,2, \cdots)$ は時間ステップ（時刻） を表す離散変数とする。各時刻における状態と行動を，そ れぞれ $s(t), a(t)$ と表す。

状態と行動の対をルールと呼び， $\left(s_{i}, a_{j}\right)$ のように表す。 そして，ルール $\left(s_{i}, a_{j}\right)$ を選択する確率 $\pi\left(s_{i}, a_{j}\right)$ を次の (1) 式で定義する。

$$
\pi\left(s_{i}, a_{j}\right):=\operatorname{Pr}\left(a(t)=a_{j} \mid s(t)=s_{i}\right) \cdots \cdots \cdots
$$

初期状態，あるいは報酬を得た直後から次の報酬を得る までのルール系列をエピソードという。エピソードに含ま れる状態集合を $\mathcal{S}_{e}\left(\mathcal{S}_{e} \subset \mathcal{S}\right)$ と表す。あるエピソードで, 同一の状態に対して異なるルールが選択されているとき, その間のルール系列を迂回系列という。現在までのすべて のエピソードで, 常に迁回系列上にあるルールを無効ルー ルと呼び，それ以外を有効ルールと呼ぶ ${ }^{(4)}$ 。本論文では, 各エピソードにおける状態 $s_{i} \in \mathcal{S}_{e}$ のうち, 迂回系列に含 まれないルールを $\left(s_{i}, \hat{a}\right)$ と表し，その選択確率を $\pi\left(s_{i}, \hat{a}\right)$ とする。

\section{3. 無効ルールの期待強化值を考慮した動的強化関 数の設計}

〈3・1〉 Profit Sharing Profit Sharingは, 各エピ ソードにおいて，初期状態から報酬を得るまでに用いたルー ルを系列として記憶しておき，報酬が得られた時点で系列上 
の各ルールの重み $w_{s(t), a(t)}$ を次の $(2)$ 式により強化する。

$$
w_{s(t), a(t)} \leftarrow w_{s(t), a(t)}+f(t, r, W)
$$

ここで, $W$ はエピソード長であり, $f(t, r, W)$ は強化関 数である。 $f(t, r, W)$ は, エピソード長 $W$ で報酬 $r$ を得 た場合の，時刻 $t$ で発火したルール $(s(t), a(t))$ に対する 強化值を与える。Profit Sharing では，任意の状態におい て，無効ルールが一番には強化されないための必要十分条 件として，合理性定理が示されている(4)。合理性定理によ れば，無効ルールが一番には強化されないためには，任意 の $t(t=1,2, \cdots, W)$ において, 次の $(3)$ 式の条件を満た せばよい。

$$
L \sum_{\tau=0}^{t-1} f(\tau, r, W)<f(t, r, W)
$$

ここで， $L$ は無効ルールと競合する有効ルールの最大個 数である。一般に $L$ の值は学習以前に知ることはできない。 しかし，Lの值が最大となるのは，唯一の無効ルールと競 合した場合である。よって，実装上は $L=J-1$ とすれば 十分である。

合理性定理を満たす最も簡単な強化関数として, 次の (4)，（5）式に示す等比減少関数が考えられる ${ }^{(4)}$ 。

$$
\begin{aligned}
f(t, r, W)= & \frac{1}{T} f(t+1, r, W) \\
& (t=1,2, \cdots, W-1) \\
T \geq & L+1 \cdots \cdots \cdots \cdots
\end{aligned}
$$

ここで, $T$ は強化減少比である。強化関数を (4) 式のよ うに決定した場合，合理性は保証される。しかし，強化值 は行動系列の長さに対して指数関数的に小さくなる。よっ て，ルーレット選択などの行動選択手法を用いて学習を進 める場合，目標状態までに多くの状態遷移を必要とする環 境では, 初期状態付近におけるルールの強化值がほぼ 0 と なり，学習が進まないという問題点がある。一方で，合理 性定理を満たす強化関数のうち, 強化值の 0 への収束速度 が最も遅い関数は，(4) 式であることが証明されており ${ }^{(5)}$, また，合理性定理は無効ルールの強化を抑制するための必 要十分条件であるため，（4）式で制限されるより大きな強 化值を与える場合，合理性は保証されない。

$\langle 3 \cdot 2\rangle$ 唯一の回帰的無効ルールが存在する状態における 無効ルールの期待強化值抑制条件＼cjkstart無効ルールを抑制す ることが最も困難な状態遷移の構造は, 図 1 のように $L$ 本 の有効ルールと唯一の回帰的無効ルールが競合する構造で ある (4)。合理性定理では, 図 1 の構造において, 無効ルー ルの最大強化值と, 有効ルールの最小強化值を考えること で抑制条件を設定している。本論文では，無効ルールの最 大強化值ではなく, 期待強化值に対して抑制条件を求める ことで，条件を緩和する。はじめに，無効ルールの期待強 化值を抑制することが最も困難な状態遷移の構造が，図 1 の構造と一致することを確認する。まず，無効ルールにつ

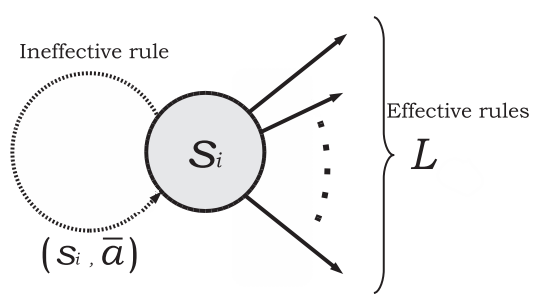

Fig. 1. The most difficult structure to suppress an ineffective rule

いて検討する。最大強化值の代わりに期待強化值を考えて も, 無効ルールは回帰的である場合が最も強化されやすい。 なぜなら，2 回，3回，‥と連続して選択される確率が最 も高い無効ルールは明らかに回帰的無効ルールだからであ る。つぎに, 有効ルールについて検討する。有効ルールの強 化值は合理性定理と同様に最小值を仮定するため, $L$ 本の 有効ルールが競合する場合を考える必要がある。以上より, 無効ルールの期待強化值を抑制することが最も困難な状態 遷移の構造は図 1 の構造といえる。すなわち, 図 1 の構造 で無効ルールの期待強化值抑制条件を求めることで，任意 の無効ルールの期待強化值を抑制できる。

以降, 強化関数 $f(t, r, W)$ は (4) 式で表される等比減 少関数とし, 提案手法における強化関数を $f^{\prime}(t, r, W)$ と 表す。いま，ある状態 $s_{i} \in \mathcal{S}_{e}$ において唯一の回帰的無効 ルール $\left(s_{i}, \bar{a}\right)$ が存在すると仮定する。ただし, その選択確 率 $\pi\left(s_{i}, \bar{a}\right)$ は $0<\pi\left(s_{i}, \bar{a}\right)<1$ である。各状態における行 動選択を独立試行とみなすと, $s_{i}$ において唯一の回帰的無 効ルール $\left(s_{i}, \bar{a}\right)$ を $n$ 回繰り返した後, 時刻 $t$ において有効 ルールを選択する確率 $p(n)(p(n):=\operatorname{Pr}(a(t-n)=\cdots=$ $\left.\left.a(t-1)=\bar{a}, a(t)=\hat{a} \mid s_{i}\right)\right)$ は, 次の $(6),(7)$ 式のよう に，幾何分布で表される。

$$
\begin{aligned}
& p(n)=\left(1-\pi\left(s_{i}, \bar{a}\right)\right)\left\{\pi\left(s_{i}, \bar{a}\right)\right\}^{n} \ldots \ldots \ldots \\
& \sum_{n=0}^{\infty} p(n)=1
\end{aligned}
$$

一方， $L$ 本の有効ルールはそれぞれ均等に選択される場合 において, 有効ルールの強化值が最も小さくなる。すなわち, $s_{i}$ における無効ルールの期待強化值よりも, 有効ルールの最 小強化值が大きくなるためには, 任意の $t(t=1,2, \cdots, W)$ において，次の（8）式の条件を満たせばよい。

$$
L \sum_{n=0}^{t-1} p(n) g(n)<f^{\prime}(t, r, W) \text {. }
$$

ここで, $g(n)$ は $p(n)$ に対応する確率変数であり, 唯一 の回帰的無効ルール $\left(s_{i}, \bar{a}\right)$ を $n$ 回繰り返し, 時刻 $t$ にお いて有効ルールを選択した場合に $\left(s_{i}, \bar{a}\right)$ に与えられる強化 值である。 $n=0$ のとき, つまり, 唯一の回帰的無効ルー ル $\left(s_{i}, \bar{a}\right)$ を選択することなく, 時刻 $t$ において有効ルール を選択する場合， $\left(s_{i}, \bar{a}\right)$ が強化されないことは自明であり， 明らかに $g(0)=0$ である。提案手法の強化減少比を $T^{\prime}$ $\left(T^{\prime} \geq 1\right)$ とおけば, $g(n)(n \geq 1)$ は次の $(9)$ 式で表さ 
Table 1. Comparison between Geometric decrease function based on theorem and proposed method

(a) Geometric decrease function

\begin{tabular}{|c||c|c|c|c|c|c|}
\hline$n$ & 0 & 1 & $\cdots$ & $n$ & $\cdots$ & $\infty$ \\
\hline$p(n)$ & 0 & 0 & & 0 & & 1 \\
\hline$g(n)$ & 0 & $f(t, r, W) \sum_{\tau=1}^{n}\left(\frac{1}{T}\right)^{\tau}$ \\
\hline$L \sum_{n=0}^{\infty} p(n) g(n)$ & \multicolumn{3}{|c|}{$f(t, r, W) \frac{L}{T-1}$} \\
\hline$T$ & \multicolumn{3}{|c|}{$T \geq L+1$} \\
\hline
\end{tabular}

れる。

$$
\begin{aligned}
g(n) & =\sum_{\tau=t-n}^{t-1} f^{\prime}(\tau, r, W) \\
& =f^{\prime}(t, r, W) \sum_{\tau=1}^{n}\left(\frac{1}{T^{\prime}}\right)^{\tau}
\end{aligned}
$$

ところで，ある確率 $\pi\left(s_{i}, \bar{a}\right)$ のもとで，エピソード長 $W$ が大きいほど唯一の回帰的無効ルール $\left(s_{i}, \bar{a}\right)$ の期待強化值 は大きくなり,さらに, $t=W$ の場合に $\left(s_{i}, \bar{a}\right)$ の期待強 化值は最大になる。よって, $t=W, W \rightarrow \infty$ として, (8) 式に（6），(9）式を代入することにより，(8）式の左辺を 次の（10）式のように変形する。

$$
\begin{aligned}
L & \sum_{n=0}^{\infty} p(n) g(n) \\
= & L f^{\prime}(W, r, W)\left(1-\pi\left(s_{i}, \bar{a}\right)\right) \\
& \cdot \sum_{n=1}^{\infty}\left\{\pi\left(s_{i}, \bar{a}\right)\right\}^{n}\left\{\sum_{\tau=1}^{n}\left(\frac{1}{T^{\prime}}\right)^{\tau}\right\} \\
= & \frac{L f^{\prime}(t, r, W)\left(1-\pi\left(s_{i}, \bar{a}\right)\right)}{T^{\prime}\left(1-\frac{1}{T^{\prime}}\right)} \\
& \cdot\left[\sum_{n=1}^{\infty}\left\{\pi\left(s_{i}, \bar{a}\right)\right\}^{n}-\sum_{n=1}^{\infty}\left\{\frac{\pi\left(s_{i}, \bar{a}\right)}{T^{\prime}}\right\}^{n}\right] \\
= & \frac{L f^{\prime}(W, r, W)\left(1-\pi\left(s_{i}, \bar{a}\right)\right)}{T^{\prime}\left(1-\frac{1}{T^{\prime}}\right)} \\
& \cdot \frac{\pi\left(s_{i}, \bar{a}\right)\left(1-\frac{1}{T^{\prime}}\right)}{\left(1-\pi\left(s_{i}, \bar{a}\right)\right)\left(1-\frac{\pi\left(s_{i}, \bar{a}\right)}{T^{\prime}}\right)} \\
= & \frac{L f^{\prime}(W, r, W) \pi\left(s_{i}, \bar{a}\right)}{T^{\prime}-\pi\left(s_{i}, \bar{a}\right)} \ldots \ldots . . .
\end{aligned}
$$

（10）式の結果より，有限の時刻 $t<\infty$ に対して明らか に次の不等式 (11) が成り立つ。

$$
L \sum_{n=0}^{t-1} p(n) g(n)<\frac{L f^{\prime}(W, r, W) \pi\left(s_{i}, \bar{a}\right)}{T^{\prime}-\pi\left(s_{i}, \bar{a}\right)} \cdots \cdots
$$

よって， $s_{i}$ における無効ルールの期待強化值よりも，有 (b) Proposed method

\begin{tabular}{|c||c|c|c|c|c|c|}
\hline$n$ & 0 & 1 & $\cdots$ & $n$ & $\cdots$ & $\infty$ \\
\hline$p(n)$ & \multicolumn{1}{||}{$\left(1-\pi\left(s_{i}, \bar{a}\right)\right)\left\{\pi\left(s_{i}, \bar{a}\right)\right\}^{n}$} \\
\hline$g(n)$ & 0 & $f^{\prime}(t, r, W) \sum_{\tau=1}^{n}\left(\frac{1}{T^{\prime}}\right)^{\tau}$ \\
\hline$L \sum_{n=0}^{\infty} p(n) g(n)$ & $f^{\prime}(t, r, W) \frac{L \pi\left(s_{i}, \bar{a}\right)}{T^{\prime}-\pi\left(s_{i}, \bar{a}\right)}$ \\
\hline$T^{\prime}$ & \multicolumn{2}{|c|}{$T^{\prime} \geq \xi\left(\pi\left(s_{i}, \bar{a}\right)(L+1)\right)$} \\
\hline
\end{tabular}

効ルールの最小強化值が大きくなるためには, 次の不等式

（12）を満たすように $T^{\prime}$ を決定すればよい。

$$
\frac{L f^{\prime}(W, r, W) \pi\left(s_{i}, \bar{a}\right)}{T^{\prime}-\pi\left(s_{i}, \bar{a}\right)} \leq f^{\prime}(t, r, W) .
$$

(12) 式から, 本論文の主要な結果として, $T^{\prime}$ の条件式 (13) が求められる。

$$
T^{\prime} \geq \xi\left(\pi\left(s_{i}, \bar{a}\right)(L+1)\right)
$$

ここで， $\xi(\cdot)$ は次の $(14)$ 式で定義される関数である。

$$
\xi(x)= \begin{cases}x & (x \geq 1) \\ 1 & (x<1)\end{cases}
$$

すなわち，(13）式を満たすように強化減少比を決定す れば，任意の無効ルールの期待強化值を抑制できる。また， （13）式を（5）式と比較することにより，提案手法では合 理性定理と比べて $\pi\left(s_{i}, \bar{a}\right) \geq(L+1)^{-1}$ のとき, 強化減少 比が $\pi\left(s_{i}, \bar{a}\right)$ 倍だけ小さく抑えられることがわかる。特に, $\pi\left(s_{i}, \bar{a}\right)<(L+1)^{-1}$ のとき, 強化減少比は最小值 1 に抑 えられる。また，極限的に $\pi\left(s_{i}, \bar{a}\right)=1$ の場合，(13) 式 は（5）式と一致する。つまり，合理性定理は唯一の回帰的 無効ルールを確率 1 で選択することを仮定していると解釈 できる。表 1 に, 合理性定理に基づく等比減少関数（表 1 (a)）と，提案手法の強化関数（表 1（b））の対応を示す。

\section{$\langle 3 \cdot 3\rangle$ 動的強化関数を用いた Profit Sharing の実装}

エピソードに含まれるそれぞれの状態 $s_{i} \in \mathcal{S}_{e}$ において, 無効ルールの期待強化值を抑制できる強化関数を考える。 提案手法では, エージェントはエピソード上のルール系列 に加えて，そのルールの選択確率も記憶する。(13）式を実 装する際，エージェントは環境に関する事前知識を持たな いため, 無効ルールの選択確率 $\pi\left(s_{i}, \bar{a}\right)$ を知ることができ ない。しかし，あるエピソードの $s_{i} \in \mathcal{S}_{e}$ において，少な くともルール $\left(s_{i}, \hat{a}\right)$ は有効ルールの一つである。そこで本 論文では，それぞれの状態において回帰的無効ルールが存 在すると仮定し, その推定選択確率 $q\left(s_{i}\right)=1-\pi\left(s_{i}, \hat{a}\right)$ を $\pi\left(s_{i}, \bar{a}\right)$ の代わりに用いる。このとき, $q\left(s_{i}\right)$ は推定值として 正確な意味を持たない。しかし, 任意の状態 $s_{i} \in \mathcal{S}_{e}$ で常に $q\left(s_{i}\right)>\pi\left(s_{i}, \bar{a}\right)$ が成り立つことから, 実装上は期待值より も安全な意味を持つ。なお, $q\left(s_{i}\right)$ を推定する他の方法も考 
えられ，たとえば， $s_{i}$ において最も強化されているルールの 選択確率を $\pi\left(s_{i}, a^{*}\right)$ として, $q\left(s_{i}\right)=1-\pi\left(s_{i}, a^{*}\right)$ と推定 する方法がある。ただし，この場合は $\pi\left(s_{i}, \bar{a}\right)=\pi\left(s_{i}, a^{*}\right)$ の可能性があり, $q\left(s_{i}\right)>\pi\left(s_{i}, \bar{a}\right)$ が保証されないため, 本 論文では扱わない。

本論文では，無効ルールの期待強化值抑制条件を利用し て, 動的な強化減少比を持つ強化関数を次の $(15) \sim(17)$ 式のように決定する。

$$
\begin{aligned}
f^{\prime}(t, r, W)= & \frac{1}{T^{\prime}(t+1)} f^{\prime}(t+1, r, W) \\
& (t=1,2, \cdots, W-1) \ldots \ldots \ldots \\
T^{\prime}(t)= & \xi\left(q(s(t)) T_{0}\right) \ldots \ldots \ldots \ldots \ldots \\
q(s(t))= & 1-\pi(s(t), \hat{a}) \ldots \ldots \ldots \ldots \ldots
\end{aligned}
$$

ここで, $T^{\prime}(t)$ は時刻 $t$ における強化減少比であり, $T_{0} \geq$ $L+1$ は強化減少比の定数である。 $T=T_{0}$ のもとで $(16)$ 式を（5）式と比較すると，提案手法では $q(s(t)) \geq T_{0}^{-1}$ の とき, 合理性定理と比べて強化減少比が $q(s(t))$ 倍だけ小 さく抑えられることがわかる。また $q(s(t))<T_{0}^{-1}$ のと き, 強化減少比は最小值 1 に抑えられる。したがって, 無 効ルールの期待強化值を考慮することで, 合理性定理に基 づく等比減少関数より小さい強化隇少比に抑えられる。

\section{$\langle 3 \cdot 4\rangle$ 提案手法と合理性定理の強化関数值の比較 提} 案手法の強化関数においても，時刻 $W$ で発火したルール $(s(W), a(W))$ への強化值は $r$ であり, 合理性定理に基づ く等比減少関数を強化関数として選ぶ場合と等しい。そし て, 時刻 $t(1 \leq t \leq W-1)$ で発火したルール $(s(t), a(t))$ への強化值の大きさについて, 強化関数に (4) 式の等比減 少関数 $f(t, r, W)$ を選ぶ場合と, 提案手法である (15) 式 の $f^{\prime}(t, r, W)$ を選ぶ場合を比較すると, 次の (18), (19) 式のようになる。

$$
\begin{aligned}
\frac{f^{\prime}(t, r, W)}{f(t, r, W)} & =\left\{\prod_{\tau=t+1}^{W} \frac{T}{T^{\prime}(\tau)}\right\} \frac{f^{\prime}(W, r, W)}{f(W, r, W)} \\
& =T^{W-t} \prod_{\tau=t+1}^{W} \frac{1}{\xi\left(q(s(\tau)) T_{0}\right)} \cdots \cdots(18) \\
& \geq 1 \ldots \ldots \ldots \ldots \ldots \ldots \ldots \ldots \ldots \ldots \ldots
\end{aligned}
$$

ただし， $T=T_{0}$ とする。(18) 式，(19）式から，任意 のルールについて $f^{\prime}(t, r, W)$ を選ぶ場合の方が強化值が大 きくなり，また， $W-t$ が大きくなるほど, $f^{\prime}(t, r, W)$ と $f(t, r, W)$ の比は大きくなることがわかる。

提案手法では，無効ルールの期待強化值を考慮すること で合理性定理で制限される条件を緩和しているため，任意 の状態で無効ルールが一番には強化されないとは限らない。 しかし, 提案手法では状態 $s_{i} \in \mathcal{S}_{e}$ に抒ける回帰的無効 ルールの推定選択確率 $q\left(s_{i}\right)$ が大きくなるほど，言い換え れば，有効ルールの一つである $\left(s_{i}, \hat{a}\right)$ の選択確率 $\pi\left(s_{i}, \hat{a}\right)$ が小さくなるほど，強化減少比は合理性定理に従う条件に 近づく。また，(17）式により $q(s(t))$ を決定すれば，現在
までの学習において無効ルールが一番に強化されていたと しても，無効ルールの期待強化值抑制条件を常に満たすこ とができる。よって，一時的には無効ルールが一番に強化 されることはあっても，多くの場合，長期的にみれば合理 性は満たされると考えられる。なお，DPS およびSDPS に おいても無効ルールの選択確率を推定する必要がある。し かし, 無効ルールの選択確率の推定值に（17）式の $q(s(t))$ を用いると, 動的強化関数を適切に設計することが困難に なる。DPS およびSDPS では, 各ルールの選択確率を決 定する一手法として, 各状態に扔いて最も選択確率が高い ルールを有効ルール，二番目に選択確率が高いルールを無 効ルールと決定する方法が採用されており，4.の計算機実 験に拉いてもこの方法を用いる。ただし，この決定方法は， 現在までの学習が合理的に行われてきたことを仮定してお り, 無効ルールが一番に強化されているような状況を想定 していないため，本論文で扱う（17）式による $q(s(t))$ の 決定方法の方が, より一般的に無効ルールの抑制を保証で きる。提案手法に扔いて，無効ルールに収束することで目 標状態へ到達できなくなるケースとしては，ある状態にお ける無効ルールが期待強化值よりも極めて大きく強化され るエピソードが起こり, その 1 エピソードの強化のみで, 無効ルールの選択確率が 1 に限りなく近づく場合が考えら れる。しかし，このようなケースが起こる確率は極めて 0 に近いため，実際の学習は適切に進むと考えられる。ある 時点から max 選択の上うに決定的な行動選択手法を用い る場合を除けば，提案手法は十分な合理性を有していると 考えられる。また, 実装する際の強化減少比の定数 $T, T_{0}$ に関して比較すれば，合理性定理においては，十分性より $T=J-1$ と決定されており, それ以上大きな值を選ぶと 報酬の分配が不十分となる恐れがある。しかし, 提案手法 では $T_{0}$ にさらに大きな值を選んでも報酬を十分に分配でき る。 $T_{0} に J-1$ よりも大きな值を選んだ場合, 合理性の観 点から見れば, 提案手法の合理性はさらに強められる。特 に，1エピソード目の学習など，ランダム選択で行動する 場合に㧧いては, $T_{0} \geq J^{2}(J-1)^{-1}$ を満たせば, 厳密に合 理性定理を満たす。なぜなら，すべての状態でランダム選 択を行うならば，任意の状態 $s_{i} \in \mathcal{S} て ゙ ~ q\left(s_{i}\right)=1-J^{-1}$ で あり, 強化関数は強化減少比 $\left(1-J^{-1}\right) T_{0} \geq J$ の等比減少 関数となるからである。また, 強化減少比の定数 $T_{0}$ を大き くすれば探索を十分に行えるため, 学習の立ち上がりは遅 くなるものの，より良い解を得られることが期待できる。

$\langle\mathbf{3 \cdot 5}$ 大局的な合理性の検討 複数回にわたるエピ ソードを考える場合，無効ルールの強化を抑制できていても， エージェントの期待獲得報酬が 0 になる可能性がある(4)。 たとえば，図 2 に扔けるすべてのルールは有効ルールであ る。しかしながら, 状態 $s_{1}$ に扔いてルール $\left(s_{1}, a ́\right)$ が強化 され, かつ, 状態 $s_{2}$ においてルール $\left(s_{2}, a\right)$ が強化される 場合, 迂回系列を構成する。合理性定理は, 無効ルールの 強化を抑制するための必要十分条件であると同時に，この ような有効ルールから構成される迂回系列の強化を抑制す 


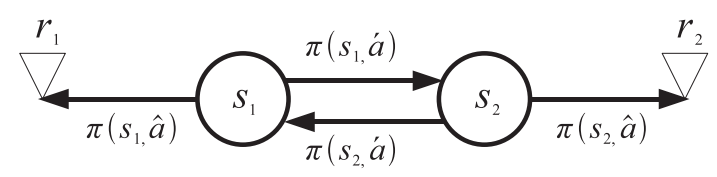

Fig. 2. A detour consists of effective rules

るための必要十分条件もである。有効ルールから構成され る迂回系列の強化を抑制する性質を大局的な合理性と呼ぶ。 本節では, 図 2 のような状態遷移の構造で 2 回のエピソー ドを考え，提案手法の大局的合理性を検討する。なお，以 降の議論は期待值を考慮しない場合の大局的な合理性の検 討過程 ${ }^{(4)(5)}$ と同じく, エピソード数が 3 以上の場合や, 各 状態における行動数が 2 以外の場合もまったく同様に考え ることができる。状態数が 3 以上の場合も同様である。よっ て, 図 2 の状態遷移の構造で 2 回のエピソードを考えるこ とで，一般性を失うことなく提案手法における大局的な合 理性を議論できる。ただし, 推定選択確率 $q(s)$ は（17）式 で決定すると仮定する。また, 報酬 $r_{1}$ を獲得する頻度と $r_{2}$ を獲得する頻度が等しい場合, 最も迂回系列が強化されや すいため, $\pi\left(s_{1}, \hat{a}\right)=\pi\left(s_{2}, \hat{a}\right)$ を仮定する。このとき，期待 強化值を考慮した大局的な合理性が満たされない場合には, ルールの重みの更新量 $\Delta w_{s, a}$ について次の不等式群 $(20)$, (21) が成り立つ。

$$
\begin{aligned}
& \Delta w_{s_{1}, \hat{a}}<\mathcal{E}\left\{\Delta w_{s_{1}, a}\right\} \\
& \Delta w_{s_{2}, \hat{a}}<\mathcal{E}\left\{\Delta w_{s_{2}, a}\right\}
\end{aligned}
$$

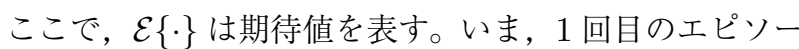
ドでエージェントが報酬 $r_{1}$ を獲得したとすれば， $q\left(s_{1}\right)=$ $\left.1-\pi\left(s_{1}, \hat{a}\right), q\left(s_{2}\right)=1-\pi\left(s_{2}, a\right)\right)$ である。一方, 2 回目の エピソードでエージェントが報酬 $r_{2}$ を獲得したとすれば, $q\left(s_{1}\right)=1-\pi\left(s_{1}, \hat{a}\right), q\left(s_{2}\right)=1-\pi\left(s_{2}, \hat{a}\right)$ である。まず, $q\left(s_{1}\right)=q\left(s_{2}\right)$ の場合について検討する。このとき，ルー ル $\left(s_{1}, \dot{a}\right)$ と $\left(s_{2}, \dot{a}\right)$ の期待強化值の和は, 唯一の回帰的無 効ルールの期待強化值と同一視できる。よって, $\langle 3 \cdot 2>0$ 議 論から次の不等式群 $(22),(23)$ が成り立つ。

$$
\begin{aligned}
& \Delta w_{s_{1}, \hat{a}}>\mathcal{E}\left\{\Delta w_{s_{1}, \dot{a}}+\Delta w_{s_{2}, a}\right\} \\
& \Delta w_{s_{2}, \hat{a}}>\mathcal{E}\left\{\Delta w_{s_{1}, \dot{a}}+\Delta w_{s_{2}, a ́}\right\}
\end{aligned}
$$

一般に，報酬 $r_{1}$ を獲得したエピソードでは $q\left(s_{1}\right) \leq q\left(s_{2}\right)$ ， かつ，報酬 $r_{2}$ を獲得したエピソードでは $q\left(s_{1}\right) \geq q\left(s_{2}\right)$ な らば，不等式群 $(22) ，(23)$ が成り立つ。（22），(23）式 の両辺をそれぞれ加えることで, 次の不等式 (24) が得ら れる。

$$
\Delta w_{s_{1}, \hat{a}}+\Delta w_{s_{2}, \hat{a}}>2 \mathcal{E}\left\{\Delta w_{s_{1}, \dot{a}}+\Delta w_{s_{2}, \dot{a}}\right\} \cdots
$$

（24）式は，不等式群（20），(21）が成り立たない，す なわち，迂回系列を構成するルールの期待強化值が抑制さ れることを意味する。よって，報酬 $r_{1}$ を獲得したエピソー ドでは $q\left(s_{1}\right) \leq q\left(s_{2}\right)$ ，報酬 $r_{2}$ を獲得したエピソードでは $q\left(s_{1}\right) \geq q\left(s_{2}\right)$ ならば, 提案手法は期待強化值を考慮した大
局的な合理性を保証できる。次に，上記の仮定を満たさない 場合について検討する。すなわち, 報酬 $r_{1}$ を獲得したエピ ソードで $q\left(s_{1}\right) \geq q\left(s_{2}\right)$, または, 報酬 $r_{2}$ を獲得したエピ ソードで $q\left(s_{1}\right) \leq q\left(s_{2}\right)$ が成り立つ場合である。このとき, （24）式は一般に成り立たない。しかしながら，(16) 式か ら求められる強化減少比 $T^{\prime}(t)$ が $T^{\prime}(t) \geq L+1$ を満たすな らば，厳密に合理性定理を満たすため，期待強化值を考慮 した大局的な合理性を検討する必要はない。よって，提案 手法では, 強化減少比の定数 $T_{0}$ を大きく設定すれば, 学習 序盤で合理性を厳密に満たすため, 図 2 の迂回系列を抑制 できると考えられる。また，任意の場合について期待強化 值を考慮した大局的な合理性を保証するためには，合理性 定理を厳密に満たす場合を除いて，目標状態からのステッ プ数 $x$ の増加に対して強化減少比が減少しなければよい。

よって, 次の式 $(25),(26)$ のように強化減少比 $T^{\prime \prime}(t)$ を決定し， $T^{\prime}(t)$ の代わりに用いる。

$$
\begin{gathered}
T^{\prime \prime}(t)=\xi\left(\breve{q}(s(t)) T_{0}\right) \ldots \ldots \ldots \ldots \ldots \ldots \ldots \\
\breve{q}(s(t))=\left\{\begin{array}{c}
\min \left\{L+1, \max _{t \leq \tau \leq W} q(s(\tau))\right\} \\
(q(s(t)) T<L+1) \\
q(s(t)) \quad(\text { otherwize })
\end{array}\right.
\end{gathered}
$$

本論文では，強化減少比を（16）式によって決定する手 法を提案手法 1 ，（25）式によって決定する手法を提案手法 2 と区別する。提案手法 2 は, 期待強化值を考慮した大局的 な合理性を保証できる反面, 目標状態からのステップ数 $x$ の増加に対して強化減少比が減少しないため, ある $x=x_{0}$ でひとたび強化減少比が大きくなると， $x>x_{0}$ における ルールの重みの強化值は急激に減少する。よって，環境の 規模が大きくなるほど，学習効率は悪化すると考えられる。

\section{4. 計算機実験}

$\langle\mathbf{4} \cdot \mathbf{1}\rangle$ 実験環境 提案手法の有効性を計算機実験に て検証する。本論文では, 提案手法 1 , 提案手法 2 , 合理性 定理, SDPS に基づく強化関数を用いて比較を行う。以降, 合理性定理に基づく等比減少関数を用いる手法を Decrease PS と呼ぶ。実験には図 3 に示す迷路走行タスク (11) を用い る。図 3 は Suttonの迷路と呼ばれるベンチマーク問題で あり, 本論文では, 図 3 のタスクに加えて, 図 3 の各状態 を 4 分割することによって, 目標状態までのステップ数を 長くしたタスクについても実験を行う。以降，このタスク を拡張したSuttonの迷路問題と呼ぶ。これらは，始点 $(\mathrm{S})$ から終点 $(\mathrm{G})$ までの経路を学習する問題であり, エージェ ントは各状態において，上下左右の行動を選択して，隣接 する 4 マスのいずれかへ移動する。この工程を 1 ステップ とする。ただし，黒いマスは壁を表し，壁かマップの外へ の移動を選択した場合，エージェントは移動できない。ま た，エージェントの状態遷移確率を以下のように設定する。 エージェントが上の行動と右の行動を選択した場合は 0.1 


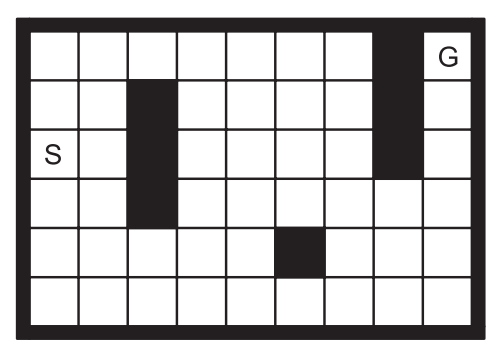

Fig. 3. Sutton's maze problem

の確率で失敗し，エージェントは移動できない。一方，下 の行動と左の行動を選択した場合は 0.1 の確率で出力が逆 になり，エージェントはそれぞれ上，右へ移動する。この とき，上の行動と右の行動は，ある状態において唯一の回 帰的無効ルールである可能性がある。一方，ある状態にお いて下（左）の行動が無効ルールならば，上（右）の行動 も無効ルールになるため, 下の行動と左の行動は, 唯一の 回帰的無効ルールにはならない。始点から終点へ到達する までを 1 エピソードとし, 終点に到達するとエージェント は環境から報酬を受け取り, 再び始点から出発する。

通常の Sutton の迷路問題では，エージェントには周囲 8 マスの視界が与えられ，視界内の状況を環境の状態として 観測する。この場合，いくつかの異なる位置を同じ状態と して知覚する不完全知覚が生じるため, エージェントにとっ て環境は部分観測マルコフ決定過程 (Partially Observable Markov Decision Processes:POMDPs）となる。ただし， 報酬を獲得するために，必ずしも同一の観測で異なる行動 を選択する必要がないため, POMDPs 環境の中でも簡単 なクラスに属する ${ }^{(12)}$ 。一方, 拡張した Suttonの迷路問題 では, 周囲 8 マスの状況を環境の状態として観測する場合, 周囲に壁が全くない状態が大きく増加することにより，ど の手法を用いても学習がきわめて困難となるため, エージェ ントには各マスの座標を環境の状態として観測できるもの とする。よって, 拡張した Suttonの迷路問題では完全知 覚であり，エージェントにとって環境は MDPs となる。な お，それぞれの迷路問題の最適解は，Suttonの迷路問題で は 14 ステップ, 拡張した Suttonの迷路問題では 28 ステッ プである。ただし，状態遷移が確率的であることにより，最 適な政策を獲得しても，最適ステップ数で終点に到達でき るとは限らないことに注意する。

$\langle\mathbf{4} \cdot \mathbf{2}\rangle$ 実験条件＼cjkstart本実験において，エージェントの行 動選択手法はルーレット選択とし, 各ルールの重みの初期 值はすべて 1 とする。報酬 $r$ は, 強化減少比を小さく抑え られる提案手法と SDPS では $r=1$ とし, 強化值が指数関 数的に減少する Decrease PS では $r=10^{6}$ と大きく設定 する。また, 提案手法では強化減少比の定数 $T_{0}$ の值を大 きくしても報酬を十分に分配できるため, $T_{0}=J=4$ に 加えて $T_{0}=6,10,20$ の場合についても検証する。SDPS については，パラメータ $P_{\epsilon}=0.05,0.1$ とする。一般に, $P_{\epsilon}$ は大きい值に設定するほど合理性が低くなり，収束は早 くなる。1 回の実験あたりのエピソード数は, Suttonの迷

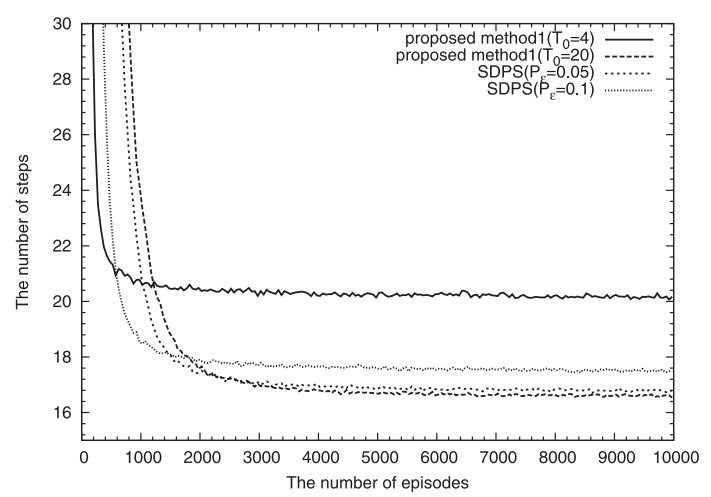

Fig. 4. Comparison of various methods in Sutton's maze problem

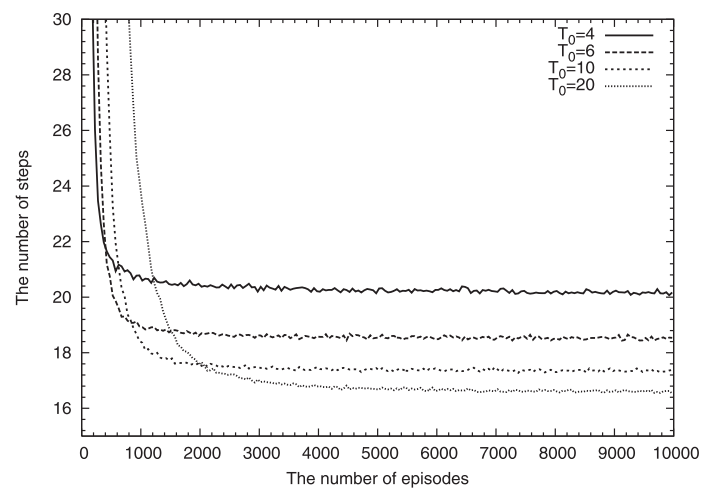

Fig. 5. Effect of the value of $T_{0}$ with proposed method 1 in Sutton's maze problem

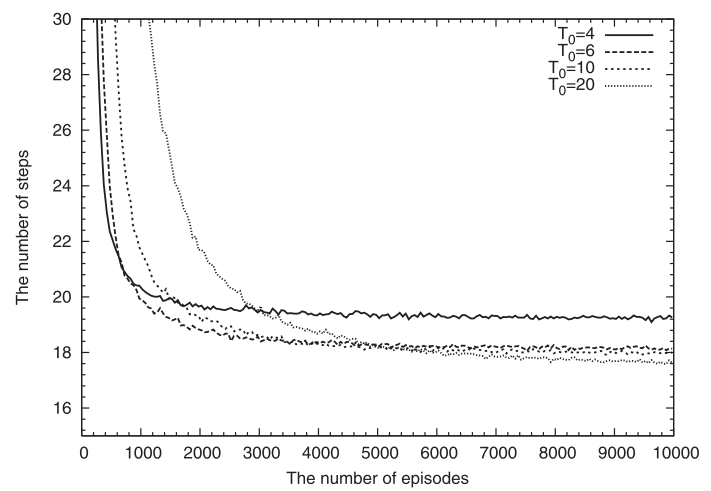

Fig. 6. Effect of the value of $T_{0}$ with proposed method 2 in Sutton's maze problem

路問題では 10,000 エピソード, 拡張したSutton の迷路問 題では 30,000 エピソードとする。そして, 乱数の系列を変 えて 100 回の実験を行う。

〈4・3〉 実験結果および考察Ｓuttonの迷路問題の実 験結果を図 $4 \sim 6$ に, 拡張したSuttonの迷路問題の実験結 果を図 7〜 に示す。なお，これらはすべて 100 回の実験 の平均を取り, かつ, 50 episode 毎の平均值をプロットし ている。図 4 9 において, $x$ 軸はエピソード数, $y$ 軸は 平均タスク達成ステップ数を表す。図 4,7 は提案手法と SDPS との比較である。また, Suttonの迷路問題と拡張し たSuttonの迷路問題において, 各手法のパラメータを変 


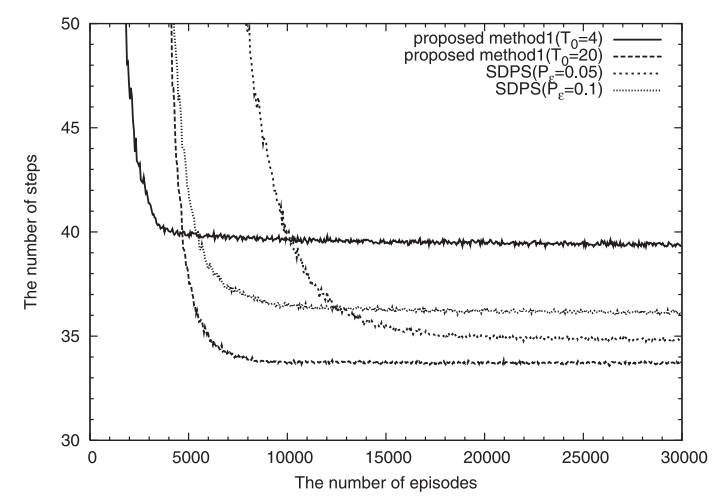

Fig. 7. Comparison of various methods in Extended Sutton's maze problem

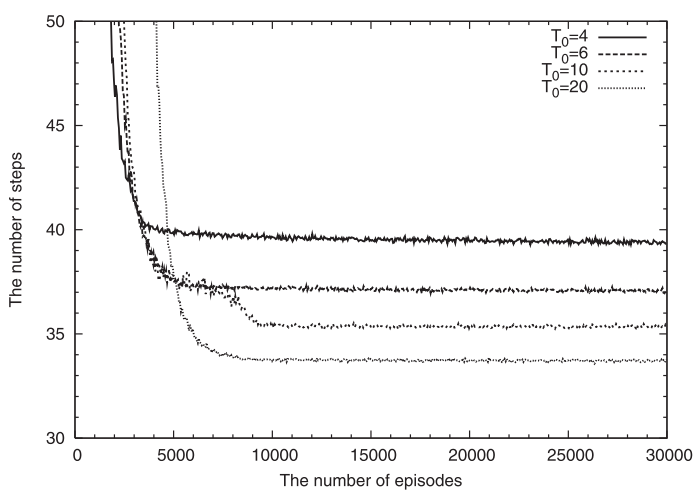

Fig. 8. Effect of the value of $T_{0}$ with proposed method 1 in Extended Sutton's maze problem

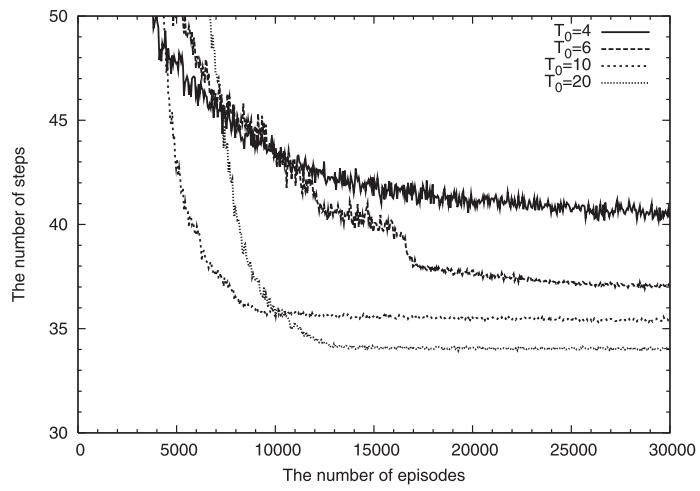

Fig. 9. Effect of the value of $T_{0}$ with proposed method 2 in Extended Sutton's maze problem

化させた場合の結果をそれぞれ図 $5 ， 6$ ，図 $8 ， 9$ に示す。な お， Decrease PS は他の手法と比べて大きく劣る結果が得 られたため, 図 4, 図 7 には結果を示していない。

まず，Suttonの迷路問題について考察する。図 5, 図 6 より, 提案手法 1 , 提案手法 2 ともに強化減少比の定数 $T_{0}$ が大きいほど獲得する解の質が向上し，収束が遅れること がわかる。これは， $T_{0}$ が小さい場合には強化減少比がすぐ に抑えられるため，エージェントが試行錯誤を十分に繰り 返すことなく学習が収束するためであると考えられる。 $T_{0}$ をさらに大きく設定することで，学習の立ち上がりは遅れ ても，よりよい解に収束することが予想される。また，図
4 から, SDPS についても, パラメータ $P_{\epsilon}$ によって獲得す る解の質と収束の早さにトレードオフが生じることがわか る。提案手法 $1\left(T_{0}=20\right)$ の収束の早さ, 収束後の解は $\operatorname{SDPS}\left(P_{\epsilon}=0.05\right)$ とほぼ同じである。提案手法 1 と提案 手法 2 を比較すると, 提案手法 1 の方が学習効率が高いこ とから, 提案手法 1 の方が学習の立ち上がり, 収束の早さ で優れている。また， $T_{0}=J=4$ の場合は提案手法 2 の 方が優れた解を獲得し， $T_{0}$ を大きく設定する場合は提案手 法 1 の方が優れた解を獲得する。これは， $T_{0}=4$ の場合に は，提案手法 1 は大局的な合理性を十分に満たすような強 化ができていないためであると考えられる。それでも， $T_{0}$ を大きく設定することで, 提案手法 1 はより優れた解を獲 得するため， $T_{0}$ を大きく設定することで，大局的な合理性 を満たしながら学習すると考えられる。一方, 提案手法 2 は，大局的な合理性が考慮される反面，学習効率が劣るた め, $T_{0}$ を大きく設定するにつれて, 提案手法 1 よりも解の 質が劣化すると考元られる。よって, 実用的には提案手法 2 よりも提案手法 1 の方が有望であると考えられる。

次に，拡張したSuttonの迷路問題について考察する。拡 張したSutton の迷路問題ではエピソード長が長くなるこ とにより, Decrease PS では強化值が指数関数的に減少す るため, 適切に学習が進まない。また, 図 7 より, SDPS は環境の規模が大きくなった影響により収束が大きく遅れ ることがわかる。しかしながら, 収束の早さに関して, 特 に提案手法 1 は環境の規模が大きくなったことによる影響 を比較的受けていない。中でも提案手法 1 の $T_{0}=20$ の場 合は, 収束の早さ, 収束する解ともにSDPSょりも優れて おり, 提案手法の有効性が確認できる。また, 図 8 および 図 9 から， $T_{0}$ を変化させる場合の効果はSutton の迷路問 題と同様であることがわかり, 提案手法 1 の $T_{0}=20$ の場 合に，すべての手法の中で最もよい解に収束している。つ まり，提案手法の収束性は環境の大きさに対して頑健であ り， $T_{0}$ を大きくしても収束が著しく遅くなることはない。 一方で, $T_{0}$ を大きくすると収束後の解が向上する性質は維 持していると言える。

SDPS では強化值の減少をより抑えるためには $P_{\epsilon}$ をよ り大きくする，つまり合理性を下げることが求められるの に対し, 提案手法では, 無効ルールの強化值を期待值で置 き換える場合に保証される合理性以上の合理性を常に保証 したうえで， $T_{0}$ を大きくすることにより，いくらでも合理 性を高めながら学習速度を制御することが可能である。ま た, 提案手法 2 のように, 大局的な合理性を考慮した強化 関数設計も可能である。実験結果から，提案手法は実用的 に十分な合理性を維持しながら, 効率よく学習を収束させ ることができると考えられる。一方で，学習の収束の早さ と得られる解のトレードオフは提案手法に扔いても依然と して残されており，今後も検討が必要であると考えられる。

\section{5. むすび}

本論文では, Profit Sharing の合理性定理について，無 
効ルールの強化值を, 最大值であったものを期待值で置き 換えることで条件を緩和し，十分な合理性を維持しながら も環境の大きさの影響をより小さく抑えることのできる動 的強化関数を提案した。また，合理性定理は本論文で提案 した強化関数の特別な場合であることを示した。提案した 強化関数は一般に強化減少比が動的となり, 合理性定理で は十分性により決定されていた $T\left(T_{0}\right)$ をパラメータとし て利用することができるため, 学習の早さと解の良さのバ ランスを調整できる。

提案手法は，報酬がたとえ小さな值でも，目標状態に近 い状態から順に強化減少比が小さく抑えられるため, 報酬 や目標状態までのステップ数に依らず，各ルールにおいて 報酬を累積できる。ただし, 学習の収束の早さと得られる 解のトレードオフは依然として残されている。今後の課題 として，このトレードオフを改善できる手法について検討 することがあげられる。

(平成 20 年 11 月 26 日受付, 平成 21 年 4 月 17 日再受付)

\section{文献}

(1) M. Yamamura, K. Miyazaki, and S. Kobayashi: "A Survey on Learning for Agents", Journal of JSAI, Vol.10, No.5, pp2329 (1995) (In Japanese)

山村雅幸・宮崎和光・小林重信 :「エージェントの学習」, 人工知能 学会誌, Vol.10, No.5, pp.23-29 (1995)

(2) C. J. C. H. Watkins and P. Dayan: "Technical note: QLearning", Machine Learning, Vol.8, pp.55-68 (1992)

(3) S. Arai, K. Miyazaki, and S. Kobayashi: "Methodology in Multi-Agent Reinforcement Learning: Approaches by QLearning and Profit Sharing", Journal of JSAI, Vol.13, No.5, pp.609-618 (1998) (In Japanese)

荒井幸代・宮崎和光・小林重信：「マルチエージェント強化学習の方 法論 $\sim Q$-Learning と Profit Sharingによる接近」, 人工知能学会 誌, Vol.13, No.5, pp.609-618 (1998)

(4) K. Miyazaki, M. Yamamura, and S. Kobayashi: "A Theory of Profit Sharing in Reinforcement Learning", Journal of JSAI, Vol.9, No.4, pp.580-587 (1994) (In Japanese) 宮崎和光・山村雅幸・小林重信:「強化学習に抢ける報酬割当ての理 論的考察」, 人工知能学会誌, Vol.9, No.4, pp.580-587 (1994)

(5) W. Uemura and S. Tatsumi: "About the Reinforcement Function for Profit Sharing", Transactions of JSAI, Vol.19, No.4, pp.197-203 (2004) (In Japanese)

植村 渉·辰巳昭治・北村泰彦:「Profit Sharing 法に拐ける強化関数 に関する一考察」, 人工知能学会論文誌, Vol.19, No.4, pp.197-203 (2004)

(6) W. Uemura, A. Ueno, and S. Tatsumi: "A Profit Sharing Method for Forgetting Past Experiences Effectively", Transactions of JSAI, Vol.21, No.1, pp.81-93 (2006) (In Japanese) 植村 渉・上野敦志・辰巳昭治:「経験に固執しない Profit Sharing 法」, 人工知能学会論文誌, Vol.21, No.1, pp.81-93 (2006)

(7) Y. Hasegawa, S. Takada, H. Nakano, S. Arai, and A. Miyauchi: "A Reinforcement Learning Method Using a Dynamic Reinforcement Function Based on Action Selection Probability", The IEICE transactions on information and systems, Vol.J89-D, No.4, pp.788-796 (2006) (In Japanese) 長谷川雄吾・高田沙都子・中野秀洋・荒井秀一・宮内 新:「行動 選択確率に基づく動的強化関数を用いた強化学習手法」, 信学論, J.89-D-I, No.4, pp.788-796 (2006)

(8) H. Nakano and A. Miyauchi: "Design of Reinforcement Functions in Profit Sharing Reinforcement Learning", IEICE technical report, Vol.106, No.574, pp.1-6 (2007) (In Japanese) 中野秀洋・宮内 新:「Profit Sharing 強化学習法に扔ける動的強 化関数の設計法」, 信学技報, Vol.106, No.574, pp.1-6 (2007)

(9) H. Kawai, A. Ueno, and S. Tatsumi: "The consideration of rationality of Profit Sharing with roulette action selection",
The 19th Annual Conference of JSAI, 1D3-03 (2005) (In Japanese)

河合宏和・上野敦志・辰巳昭治：「ルーレット選択を用いた Profit Sharing 強化学習における合理性についての一考察」, 2005 年度人 工知能学会全国大会（第 19 回）論文集，1D3-03 (2005)

10) T. Matsui and H. Ohwada: "Rationality of Profit Sharing Based on Expected Value", The 22th Annual Conference of JSAI, 3A2-1 (2008) (In Japanese)

松井藤五郎・大和田勇人：「Profit Sharing の期待值に基づく合理 性」, 2008 年度人工知能学会全国大会（第 22 回）論文集，3A2-1 (2008)

(11) R. Sutton: "Integrated architecture for learning, planning, and reacting based on approximating dynamic programing", in Proc. of the 7th International Conference on Machine Learning, pp.216-224 (1990)

12) K. Miyazaki, S. Arai, and S.Kobayashi: "Learning Deterministic Policies in Partially Observable Markov Decision Processes", Transactions of JSAI, Vol.14, No.1, pp.148-156 (1999) (In Japanese)

宮崎和光・荒井幸代・小林重信：「POMDPs 環境下での決定的政策 の学習」, 人工知能学会誌, Vol.14, No.1. pp.148-156 (1999)

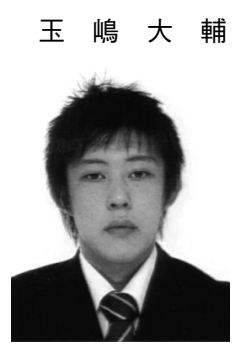

（正員） 1985 年 1 月 25 日生。 2007 年千葉大学 工学部電子機械工学科卒業, 2009 年同大学院工学 研究科人工システム科学専攻博士前期課程修了。 現在, オムロンに勤務。在学中, 強化学習の研究 に従事。

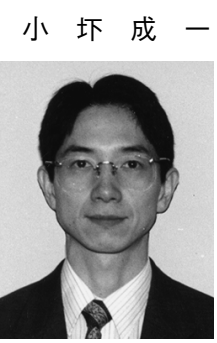

（上級会員） 1964 年 7 月 7 日生。 1992 年千葉大 学大学院自然科学研究科生産科学専攻博士課程修 了。同年千葉大学工学部助手, 1997 年同助教授, 同年同大学院自然科学研究科助教授, 2007 年同 大学院工学研究科准教授となり現在に至る。確率 的最適化, 学習の研究に従事。博士 (工学)。

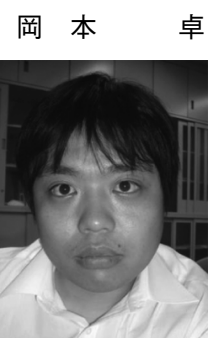

（正員） 1980 年 8 月 25 日生。 2007 年慶應義塾 大学大学院理工学研究科基礎理工学専攻博士課程 修了。2007 年千葉大学大学院工学研究科助教任 用，現在に至る。非線形力学系を計算モデルとす る最適化手法に関する研究に従事。博士 (工学)。

平 田 廣 則 (上級会員) 1948 年 6 月 2 日生。 1976 年 東京工

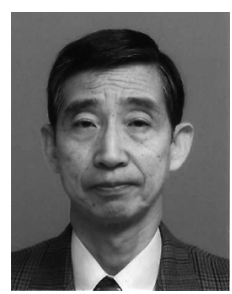
業大学大学院電気工学専攻博士課程修了。同年千 葉大学工学部助手, 1981 年同助教授, 1994 年同 教授, 2007 年同大学院工学研究科教授となり現在 に至る。大規模システムのモデリング, 解析と設 計に関する基礎的理論に興味を持つ。工学博士。 